\title{
A Study on Antenatal Corticosteroids to Reduce Neonatal Morbidity and Mortality
}

\author{
Geisha Merin Varghese ${ }^{1, *}$, Anju Antony ${ }^{2}$, Thasleena ${ }^{3}$ \\ ${ }^{1}$ Seven Hills College of Pharmacy, Tirupati, Andhra Pradesh, INDIA. \\ ${ }^{2}$ Clinical Pharmacist, Travancore Medcity Hospital, Kollam, Kerala, INDIA. \\ ${ }^{3}$ Clinical Pharmacist, Aster Medcity, Cochin, Kerala, INDIA.
}

\begin{abstract}
The prime factor for insufficient surfactant production and pulmonary immaturity is birth of a new-born before reaching the term. Objectives: The current study is to estimate the effect of antenatal steroid administration to women before anticipated preterm labor and to assess the importance of corticosteroids for preventing neonatal mortality due to preterm birth complications. Materials and Methods: A prospective observational study on women at high risk of preterm delivery between 24 and 37 weeks of gestation were included in the study and Pregnancies complicated by congenital anomalies, chromosomal abnormalities, or multifetal gestation and women expected to deliver in less than $12 \mathrm{hr}$ for any reason was excluded. Results: Eighteen women (90\%) received betamethasone and two $(10 \%)$ received dexamethasone. Fifteen women $(75 \%)$ received a complete course of antenatal steroids; five $(25 \%)$ woman received one of a planned two-dose course of betamethasone. The most common reason for exclusion was the expectation that delivery would occur within $24 \mathrm{hr}$ which was determined in 8 of 30 women who did not meet the eligibility criteria. Length of hospital stay for most of the infants was between 3-5 days but few discharged after 5 days. The discharged days were extended due to feeding problem. Conclusion: In this study we concluded that betamethasone was the most common antenatal steroid prescribed among the steroids to women before anticipated preterm labor and also we found that with the use of antenatal steroids at the right time, the neonatal death rates can be reduced.
\end{abstract}

Key words: Antenatal corticosteroids, Preterm labor, Pulmonary immaturity, Neonatal mortality, Length of hospital stay.

\section{INTRODUCTION}

Labor before 37 weeks of gestation defined as preterm birth is the main determinant of postnatal mortality and morbidity. ${ }^{1}$ The incidence of preterm birth in the developed world is between $7-12 \% .^{2}$ Respiratory Distress Syndrome (RDS), also known as hyaline membrane disease was the primary cause of morbidity and mortality in preterm new-born. ${ }^{1}$ Maturation of foetal lungs is dependent on surfactant, which is a complex molecule. The prime factor for insufficient surfactant production and pulmonary immaturity is birth of a newborn before reaching the term. ${ }^{2}$ Antenatal steroid treatment for women who are at risk of preterm delivery has emerged as the most effective intervention for the prevention of RDS, reducing early neonatal mortality and morbidity. ${ }^{3}$ Corticosteroids act by promoting the expressions of proteins that accelerate the functional and structural maturity of pulmonary cells and other organs. The physiological effects on the lungs result from the production of proteins and enzymes involved in the production of phospholipids by type 2 pneumocytes. The physiological effects include improvement of pulmonary expansion, reduction in vascular permeability, improvement of respiratory function and response to postnatal surfactants. ${ }^{4}$ The National Institutes of Health (NIH) sponsored a Consensus Development Conference on the effect of corticosteroids for fetal lung maturation on perinatal outcomes, concluding that a single course of corticosteroids should be considered for women at risk of preterm delivery. It concluded that the optimal benefit of corticosteroids lasted for 7 days and further research was needed to determine the
DOI: 10.5530/ijopp.13.1.13

Address for correspondence: Dr. Geisha Merin Varghese, Doctor of Pharmacy (Pharm.D), Assistant Professor, Department of Pharmacy Practice, Seven Hills College of Pharmacy, Tirupati-517101, Andhra Pradesh, INDIA.

Phone no: +91 9442895302 Email Id: meringeisha@gmail. com

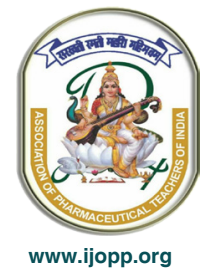


possible benefit of repeat corticosteroid doses 7 days after the initial course. ${ }^{5}$

\section{Objectives of the study}

The objective of the current study is to estimate the effect of antenatal steroid administration to women before anticipated preterm labor and to assess the importance of corticosteroids for preventing neonatal mortality due to preterm birth complications.

\section{MATERIALS AND METHODS}

A prospective observational study was carried out for a period of two months in the gynecology department of a tertiary care hospital at Tamil Nadu. Women at high risk of preterm delivery between 24 and 37 weeks of gestation were included in the study. Pregnancies complicated by congenital anomalies, chromosomal abnormalities, or multifetal gestation and women expected to deliver in less than $12 \mathrm{~h}$ for any reason was excluded from the study. The source of data was patient case notes and medication charts.

\section{RESULTS AND DISCUSSION}

\section{Characteristics of the Participants}

Of the 30 charts screened of women, 20 pregnant women met inclusion criteria and had been treated with antenatal corticosteroids. The most prevalent gestational age was less than or equal to 34 weeks and 6 day of gestation $(75 \%)$. The maternal age of the patient was found to be between 25-30 years (65\%) and observing the gravidity $(60 \%)$ were of primigravida. The method of delivery of the womens receiving antenatal steroids was cesarean section $(95 \%)$ and time taken for delivery was $24-48 \mathrm{hr}$ 12 patients $(60 \%)$ and $48 \mathrm{hr}-7$ days was 8 patients $(40 \%)$ (Table 1).

Eighteen women (90\%) received betamethasone and two $(10 \%)$ received dexamethasone (Figure 1).

Fifteen women $(75 \%)$ received a complete course of antenatal steroids; five (25\%) woman received one of a planned two-dose courses of betamethasone. The most common reason for exclusion was the expectation that delivery would occur within $24 \mathrm{~h}$ which was determined in 8 of 30 women who did not meet the eligibility criteria

\section{Neonatal Outcome}

There were no stillbirths or neonatal deaths within $72 \mathrm{hr}$. The rate of the composite outcome of severe respiratory complications was lower in the neonates of betamethasone received antenatal women's.

\section{Table 1: Characteristics of the Participants.}

\begin{tabular}{|c|c|}
\hline Characteristic & $\begin{array}{l}\text { Antenatal steroids } \\
\qquad(N=20)\end{array}$ \\
\hline \multicolumn{2}{|l|}{ Gestational age at trial entry } \\
\hline $\begin{array}{c}\leq 34 \text { wk } 6 \text { days } \\
35 \text { wk } 0 \text { days to } 35 \text { wk } 6 \text { days }\end{array}$ & $\begin{array}{l}15(75 \%) \\
5(25 \%)\end{array}$ \\
\hline $\begin{array}{c}\text { Preeclampsia or gestational } \\
\text { Hypertension }\end{array}$ & $7(35 \%)$ \\
\hline $\begin{array}{l}\text { Gestational diabetes } \\
\text { Hypothyroidism }\end{array}$ & $\begin{array}{l}5(25 \%) \\
2(10 \%)\end{array}$ \\
\hline \multicolumn{2}{|l|}{ Maternal age } \\
\hline $\begin{array}{c}<25 \text { years } \\
25-30 \text { years } \\
>30 \text { years }\end{array}$ & $\begin{array}{c}3(15 \%) \\
13(65 \%) \\
4(20 \%)\end{array}$ \\
\hline \multicolumn{2}{|l|}{ Gravidity } \\
\hline $\begin{array}{l}1 \\
2 \\
3\end{array}$ & $\begin{array}{l}12(60 \%) \\
6(30 \%) \\
2(10 \%)\end{array}$ \\
\hline \multicolumn{2}{|l|}{ Method of delivery } \\
\hline $\begin{array}{l}\text { Vaginal } \\
\text { Cesarean }\end{array}$ & $\begin{array}{c}1(5 \%) \\
19(95 \%)\end{array}$ \\
\hline \multicolumn{2}{|l|}{ Time of delivery } \\
\hline $\begin{array}{c}24-48 \mathrm{hr} \\
48 \mathrm{hr}-7 \text { days }\end{array}$ & $\begin{array}{l}12(60 \%) \\
8(40 \%)\end{array}$ \\
\hline
\end{tabular}

\section{ANTENATAL STEROIDS}

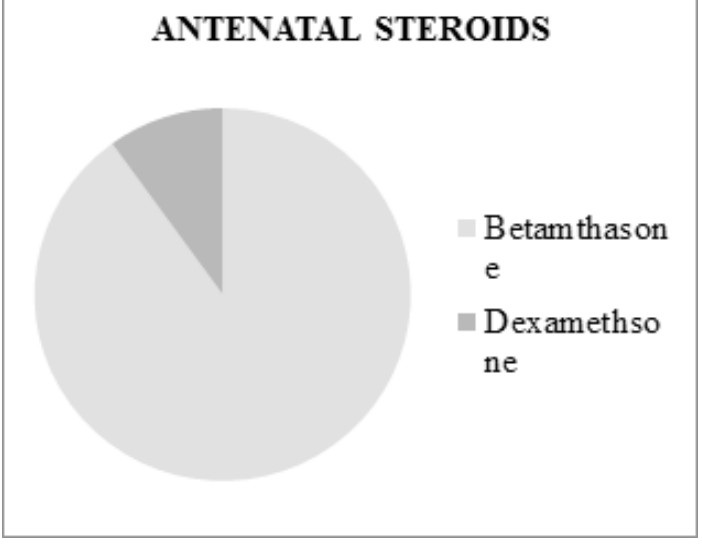

Figure 1: Calibration curve for the drug with reagent $\mathrm{C}$.

The rates of the respiratory distress syndrome (35\%), apnea $(35 \%)$, pneumonia and transient tachypnea of the newborn $(5 \%)$ were significantly lower in the in the neonates of betamethasone received antenatal women, there was also a lower rate of resuscitation at birth (40\%) and surfactant use (30\%) (Table 2 and Figure 2).

Length of hospital stay for most of the infants was between 3-5 days but few discharged after 5 days. The discharged days were extended due to feeding problem (Table 3). 


\section{Table 2: Neonatal Respiratory Outcomes.}

Outcome

\begin{tabular}{cc} 
Outcome & Betamethasone (N= 20) \\
\hline CPAP or BPAP & $7(35 \%)$ \\
Neopuff ventilation & $1(5 \%)$ \\
Stillbirth or neonatal death $\leq 72 \mathrm{hr}$ & 0 \\
after Birth & \\
Respiratory distress syndrome & $7(35 \%)$ \\
Transient tachypnea of the newborn & $1(5 \%)$ \\
Apnea & $7(35 \%)$ \\
Surfactant use & $6(30 \%)$ \\
Hypoglycemia & $3(15 \%)$ \\
Hyperbilirubinemia & $11(55 \%)$ \\
\hline
\end{tabular}

Table 3: Length of Hospital Stay of Neonates. Length of hospital stay Number of neonates

\begin{tabular}{cc}
\hline$<3$ days & 2 \\
$3-5$ days & 12 \\
$>5$ days & 6 \\
\hline
\end{tabular}

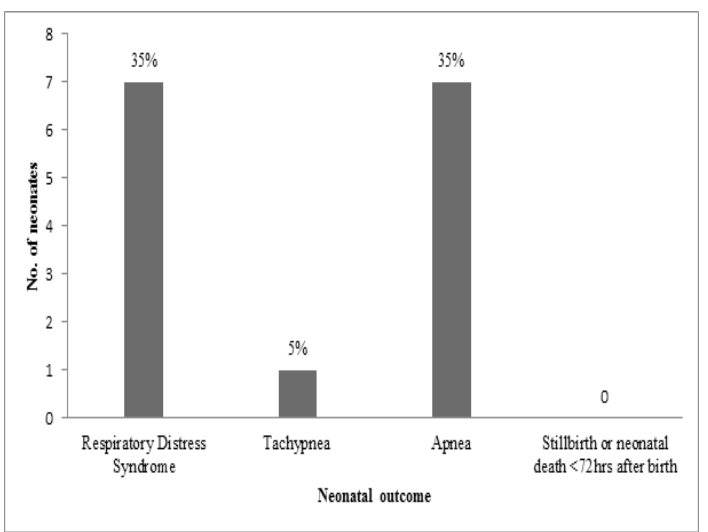

Figure 2: Neonatal Outcomes.

C Gyamfi Bannerman et al. concluded that Severe respiratory complications, transient tachypnea of the newborn, surfactant use and broncho pulmonary dysplasia also occurred significantly less frequently in the betamethasone group which is comparable with our study.

The positive impact of antenatal steroids in our study was comparable with the study conducted by $\mathrm{MH}$ Malloy. ${ }^{6}$

\section{CONCLUSION}

In this study we concluded that betamethasone was the most common antenatal steroid prescribed among the steroids to women before anticipated preterm labor and also, we found that with the use of antenatal steroids at the right time, the neonatal death rates can be reduced. Further studies are required to optimize the use of antenatal corticosteroids.

\section{ACKNOWLEDGEMENT}

We express our sincere thanks to the physicians and nurses in the gynecology department and neonatal units of Kovai Medical Hospital, Coimbatore, without whom this study would not have been possible.

\section{CONFLICT OF INTEREST}

The authors declare no conflict of interest.

\section{ABBREVIATIONS}

RDS: Respiratory distress syndrome; NIH: National Institutes of Health; CPAP: Continous Positive Airway Pressure; BPAP: Bilevel Positive Airway Pressure.

\section{SUMMARY}

The use of antenatal corticosteroids at right time with appropriate dose reduces the neonatal mortality.

\section{REFERENCES}

1. Shahzad F, Umar N. Impact of antenatal corticosteroids on frequency and mortality due to respiratory distress syndrome in preterm neonates. Ayub Med Coll Abbottabad. 2016;28(4):698-701.

2. Bannerman CG, Thom EA, Blackwell SC. Antenatal Betamethasone for Women at Risk for Late Preterm Delivery. The New England Journal of Medicine. 2016;374(14):1311-20.

3. Soysal S, Yildizhan B. Should antenatal corticosteroids be done after 34 weeks of gestation. Eastern Journal of Medcine. 2016;21(3):154-7.

4. Kambafwile JM, Cousens S, Hansen T, Lawn JE. Antenatal steroids in preterm labour for the prevention of neonatal deaths due to complications of preterm birth. International Journal of Epidemiology. 2010;39(1):i122-33.

5. Bittar RE, Francisco RPV, Zugaib M. Antenatal Corticosteroid Administration for Reducing the Risk of Neonatal Morbidities from Prematurity. RBGO Gynecology and Obstetrics. 2016;38(3):117-9.

6. Malloy MH. Antenatal steroid use and neonatal outcome: United States. Journal of Perinatology. 2012;32(9):22-7. 